Postprint: TEACHERS’ PERCEPTIONS OF AIDED AAC IMPLEMENTATION

Please note: This is the postprint version of the following article;

Tönsing, K. M., \& Dada, S. (2016). Teachers’ perceptions of implementation of aided AAC to support expressive communication in South African special schools: a pilot investigation. Augmenttive and Alternative

Communication, Early online, 1-23. http://doi.org/10.1080/07434618.2016.1246609

\title{
Teachers' Perceptions of Implementation of Aided AAC to Support Expressive Communication in South African Special Schools: a Pilot Investigation
}

Kerstin M. Tönsing and Shakila Dada

University of Pretoria

Centre for Augmentative and Alternative Communication, University of Pretoria

This research project was funded by the National Research Foundation (NRF) of South Africa and the Research Development Programme of the University of Pretoria. Opinions expressed and conclusions arrived at are those of the author and are not necessarily the NRF or the University of Pretoria. The authors would like to thank the teachers who participated in the study, the school staff who provided assistance with logistical arrangements, and Ms. Jeanette Sothman, who acted as a research assistant.

Correspondence regarding this article should be addressed to Kerstin Tönsing, Centre for Augmentative and Alternative Communication, University of Pretoria, Hatfield, Pretoria, 0002, South Africa. E-mail: kerstin.tonsing@up.ac.za

Declaration of interest: The authors report no conflict of interest. The authors alone are responsible for the content and writing of this paper. 


\begin{abstract}
Although the provision of assistive technology for students with disabilities has been mandated in South African education policy documents, limited data are available on the implementation of aided augmentative and alternative communication (AAC) in classrooms. This pilot investigation used a concurrent mixed-methods survey design to determine the extent to which aided AAC was implemented to foster students' expressive communication in preschool to Grade 3 classrooms in special schools from six urban school districts in the Gauteng (the smallest, most affluent and most densely populated of the nine South African provinces), and also obtained teachers' perceptions of this process. A total of 26 teachers who taught students who used aided AAC for expression participated. Although there is evidence of provision and also implementation of aided AAC in classrooms, various limitations still exist. Teachers identified an array of factors that influenced the implementation of aided AAC, including those related to themselves, the classroom context, the characteristics of aided AAC, students using AAC, and other stakeholders. These factors are discussed in the light of international literature as well as the local context, and are used as a basis to suggest a research agenda for AAC in the South African education system.
\end{abstract}

Keywords: Aided augmentative and alternative communication (AAC); Expressive communication; Students with limited speech; Special schools; Teachers 
Communication is central to classroom learning because it is the medium through which instruction takes place, meaning is generated, and knowledge and skills are shared and demonstrated (Kathard \& Pillay, 2015). Students who cannot use speech adequately to meet all of their communication needs are typically at high risk for reduced participation and exclusion from classroom activities (Raghavendra, Olsson, Sampson, Mcinerney, \& Connell, 2012). Without reliable methods to respond to assessment tasks, their potential is often underestimated and therefore remains unrealized (Calculator, 2009). These students may benefit from augmentative and alternative communication (AAC; Calculator \& Black, 2009; Kent-Walsh \& Light, 2003),(Calculator \& Black, 2009; Kent-Walsh \& Light, 2003) which includes the use of techniques, strategies, aids, and symbols to supplement oral speech or substitute speech that is not functional (American Speech-Language Hearing Association [ASHA], 2015). Aided AAC, the focus of this study, refers to both electronic options such as speech-generating devices (SGDs) and nonelectronic options such as communication boards and picture exchange systems (ASHA, 2015). Through the use of AAC, students can be afforded the opportunity to be active participants in their own learning through engaging in social and educational meaning-making dialogue (Calculator, 2009).

Under the Apartheid regime (1948 - 1994), South Africa’s education system was segregated by race and further by the presence of a disability (for decisions on eligibility for mainstream versus special schools; Kathard et al., 2011). Special schools were those catering exclusively to students with disabilities, with further segregation according to type of disability (e.g., hearing impairment, visual impairment, cerebral palsy, etc.). After South Africa's transition to a constitutional democracy in 1994, the newly elected government committed to an inclusive education system that would not exclude students on any basis (Section 29, The 
Constitution of the Republic of South Africa, 1996; Education White Paper 6, Department of Education [DoE], 2001). Somewhat controversially, special schools were not abolished, but envisioned as part of an integrated system that would include special, full service, and mainstream schools. Currently, special schools are officially defined as "schools equipped to deliver education to learners requiring high-intensive educational and other support either on a full-time or a part-time basis" (DoE, 2010, p. 8). De facto they continue to cater almost exclusively to students with disabilities, and are still officially designated as catering to students with specific types of disabilities (e.g., autism spectrum disorder, cerebral palsy, or intellectual disability). Schools that are termed full service or inclusive are defined as "mainstream education institutions that provide quality education to all students by supplying the full range of learning needs in an equitable manner" (DoE, 2010, p. 7). They should have human and material resources available to support students with a variety of barriers to learning.

Special schools are mandated to support students with high support needs, prepare them as far as possible to enter mainstream schools, and act as resource centers for mainstream and full service schools (DoE, 2001). Progress in implementing an inclusive education system has been alarmingly slow (DoE, 2015; Human Rights Watch, 2015) and hampered by poor policy directives, poor enforcement of policies and monitoring of compliance, high student-teacher ratios, lack of funding, and lack of support to schools and teachers (Donohue \& Bornman, 2014). Previous racial disparities in educational provision (e.g., disparities in resources available to schools) still manifest in vast regional differences in material, financial and human resources available to schools in different areas, with the better-resourced schools typically being situated in urban areas historically reserved for white South Africans (Kathard et al., 2011). Furthermore, cultural and linguistic diversity in urban classrooms is a common phenomenon, presenting a 
further challenge to educators (Kathard et al., 2011). The number of students with disabilities enrolled in special schools remains higher than those attending mainstream schools (DoE, 2015), and concerns have been raised about special schools' capacity to prepare students for mainstream schools (Human Rights Watch, 2015). Improved quality of education in special schools (including appropriate assistive technology provision) is seen as a short-term strategy, a stepping-stone as part of a longer-term vision to eventually promote educational inclusion of most students with disabilities in mainstream schools (DoE, 2007, 2015; Human Rights Watch, 2015).

Various South African education policy documents have mandated the provision of appropriate assistive technology (with specific mention of aided AAC) for students with disabilities (DoE 2007, 2010). According to a recent report released by the DoE (2015), some provincial education departments procured assistive technology (including aided AAC) during the period 2012-2014, but central procedures for procurement, maintenance, effectiveness monitoring, and teacher training were not in place. Statistics regarding assistive technology implementation in special schools were also lacking.

In this study, we were particularly interested, first, in the extent to which aided AAC was implemented in classrooms in a metropolitan area in South Africa to facilitate expressive communication for students with limited speech; and second, in teachers' perceptions of this process. Teachers play a pivotal role in supporting students who use aided AAC in classrooms, as confirmed by studies and reports from both developed and developing countries (e.g., Clarke, McConachie, \& Price, 2001; Hunt, Soto, Maier, Müller, \& Goetz, 2002; Mukhopadhyay \& Nwaogu, 2009; Patel \& Khamis-Dakwar, 2005).

Previous studies found positive attitudes among general education and/or special 
education teachers (who did not necessarily have experience with AAC implementation) towards AAC in general (Soto, 1997) and aided AAC in particular (Dada \& Alant, 2001, 2002), which bodes well for the future implementation of aided AAC. Teachers have also reported on a complex array of factors that could contribute or hinder successful communication, participation, and inclusion of students in need of/using AAC within a classroom environment, including (a) student ability; (b) availability and integrity of aided AAC; (c) teacher skill, knowledge, expectations, and self-efficacy; (d) peer abilities and attitudes; (e) demands of the classroom context; and (f) collaboration between team members (De Bortoli, Arthur-Kelly, Foreman, Balandin, \& Mathisen, 2011; Kent-Walsh \& Light, 2003). De Bortoli et al. (2011) suggested that these factors needed to be understood from a systemic perspective, in order to recognize their interrelatedness and complexity. According to Raghavendra, Bornman, Granlund, and Björck-Akesson (2007), the International Classification of Functioning, Disability and Health (ICF; World Health Organization [WHO], 2001) may provide such a systemic perspective on AAC implementation, as this bio-psychosocial framework illustrates how activity levels and participation are ultimately determined by a complex interplay between extrinsic (environmental) and intrinsic factors (body functions and structures, as well as personal factors). Because we wanted to understand the unique barriers and facilitators associated with supporting students who use aided AAC for expression, this study aimed to determine (a) the extent to which aided AAC such as communication boards and SGDs were provided and implemented in preschool classrooms (catering to children aged 3-5 years) and Foundation phase classrooms (i.e., Kindergarten and the first three grades of formal primary education with students typically aged 5-9 years) in special schools in six school districts in a metropolitan area in South Africa to facilitate expressive communication for students with limited speech, and (b) teachers' 
perceptions about factors influencing implementation of aided AAC in classrooms.

\section{Method}

\section{Participants}

The ethics committee of the authors' university approved the study. The study focused on six urban school districts of the Gauteng province. Gauteng is the smallest of the nine South African provinces, taking up only $1.5 \%$ of the total land area of the country, yet home to $25 \%$ of its population (Statistics South Africa, 2015). Situated in the North East of the country, it includes the largest city (Johannesburg), the administrative capital (Pretoria), as well as densely populated industrial areas. It is the economic center of the country, and is responsible for a third of the gross domestic product (Statistics South Africa, 2011). Although Gauteng has the highest average household income of all provinces, the province does not fare as well on other economic indicators (e.g., proportion of households that live in informal dwellings, have access to electricity and/or running water), suggesting significant economic disparities in the population (Statistics South Africa, 2012). The particular school districts included in the study were chosen because staff in many of the special schools had received training in implementation of aided AAC, from either academic institutions or technology providers, and also because of the physical proximity of the schools. From the 58 special schools situated in these districts, those designated as schools that accommodated students with (a) autism spectrum disorders, (b) physical disabilities, (c) cerebral palsy, and (d) severe intellectual disabilities were selected, as these schools were most likely to include students with limited speech. Schools for students with sensory impairment, epilepsy, and mild intellectual disabilities were excluded. The provincial education department gave permission to contact these special schools. A research assistant contacted each school, and used a telephonic script (see Appendix A) to obtain information about 
the implementation or non-implementation of aided AAC in both the preschool and Foundation phase classes of the schools. The research assistant asked to speak to someone knowledgeable about aided AAC and was referred to either a speech-language pathologist (SLP), an occupational therapist (OT), or a physiotherapist at 18 of the schools; and to an administrator at seven of the schools. Of the 25 schools contacted, 22 accommodated students with limited speech in the preschool and/or Foundation phase classes and aided AAC (e.g., communication boards, SGDs) was present in 20 schools, yet only nine schools (as per the contact person) used aided AAC to assist students in the preschool and/or Foundation phase to express themselves in class.

The principals of eight of the nine schools gave permission to recruit teachers from the school: four schools were designated for students with cerebral palsy, three for students with severe intellectual impairments, and one for students with autism spectrum disorders. Therapists or school principals identified a total of 27 teachers (across the eight schools) who met the selection criterion, that is, they taught at least one student (in the preschool or Foundation phase classes) who used aided AAC for expression in the classroom. In all, 26 teachers gave written consent and participated in the study. All of the teachers were female and ranged in age from 25 to 65 years $(M=42.5 ; S D=15.3)$. Their overall teaching experience ranged from 1 to 37 years $(M=15.7 ; S D=11.6)$, and their experience in teaching students with limited speech ranged from six months to 37 years $(M=9.3 ; S D=7.3)$. All 26 teachers had received some type of training regarding aided AAC: $73 \%$ had received training in the form of workshops and $75 \%$ had received training from an SLP. Only five teachers (19\%) had received training as part of a formal qualification - in all five cases this comprised a 2-year part-time post-graduate qualification in AAC. 


\section{Design}

We used a concurrent mixed-methods design and a questionnaire to obtain quantitative and qualitative data from teachers. We analyzed closed questions quantitatively and open-ended questions qualitatively using an inductive thematic approach. We then combined both qualitative and quantitative data to arrive at a deeper understanding of the phenomenon investigated.

\section{Questionnaire}

The questionnaire administered to the teachers consisted of 20 closed-and open-ended questions (Appendix B). Of these questions, nine pertained to teacher and student demographics. An additional question asked about the number and types of aided AAC implemented in the classroom. We devised the remaining questions based on a review of previous research regarding teachers' perceptions and experiences of AAC implementation (Calculator \& Black, 2009; Hunt et al., 2002; Kent-Walsh \& Light, 2003; Soto, 1997). These questions pertained to teachers' perceptions about the usefulness of aided AAC, their role and competence in implementation, the challenges they experienced, the support they received during the process, and their training needs. The questionnaire was reviewed by two consultants (one teacher and one SLP who had previously been employed by and provided AAC services at two of the participating special schools), who suggested minor wording changes. It was also piloted with seven teachers in a private special school who taught students who used aided AAC; amendments were made to some questions to increase clarity.

\section{Data Collection and Analysis}

The researcher (first author) scheduled an appointment with the teacher(s) at each of the schools at a time suitable for them. Depending on schedules, teachers were either seen 
individually $(n=8)$ or in groups, varying from two to six teachers per group $(n=18)$. The researcher explained the study and obtained written consent, and also explained terminology and questions that could potentially cause confusion. Teachers then completed the questionnaire, with the researcher present and available to provide clarification as needed. Clarification requests were minimal and pertained mostly to the difference between aided AAC that was shared among students versus those systems that were not (Question 10). The researcher transferred quantitative data to an Excel $^{\mathrm{TM}}$ spreadsheet. We used descriptive statistics to summarize quantitative data.

The questionnaire also contained two open-ended questions that probed for qualitative data. The first question concerned teachers' perceptions of possible solutions for any challenges they experienced in implementation of aided AAC. The second requested written comments from teachers that would help us understand their experiences and perceptions regarding the use of aided AAC by students in their class. In addition, teachers were given the opportunity to write clarifying comments for some closed questions, including a question related to the usefulness of aided AAC, a question regarding their perceptions of their own competence, and two questions regarding further training. These comments were also qualitatively analyzed. Teachers' written comments were retyped per teacher and per question into an excel spreadsheet. The researcher then coded the comments by means of an inductive descriptive coding process in the first cycle of coding (Saldaña, 2013). Comments were also divided into segments of text during the initial coding process so that each segment of text was assigned its own code. A list of codes was developed and refined and grouped into provisional themes and subthemes. These codes were then assigned to the text segments in a second cycle of data coding. The second author reviewed the coding. Agreement on the coding was calculated by dividing the number of agreements 
(173) by the number of agreements plus disagreements (182). Agreement was 95\%. Authors discussed disagreements and reached consensus on the final coding.

\section{Results}

\section{Quantitative Data}

Provision and implementation of aided AAC in special schools. The teachers who completed the questionnaire reported that, of the 288 students from the 26 classrooms, 130 (45\%) had limited speech. Across the eight schools, teachers reported that there were 133 aided AAC systems that were being used in preschool and Foundation phase classes to aid expression of students with limited speech. Of these, 89 (67\%) were personal systems, used exclusively by one student; while 44 (33\%) were shared among students. Of the 130 students with limited speech, 62 (48\%) used one or more personal system. Of the 89 personal systems, $77(87 \%)$ were nonelectronic and 12 (13\%) were electronic; 10 were owned by the students/families, whereas the other 79 were owned by the school but were allocated for exclusive use by one student. A total of 35 students either took their personal aided AAC system home or had a duplicate of it at home. Most of these systems were nonelectronic $(n=34)$; one, which was electronic, was taken home because it had been purchased by the family rather than the school.

Of the 130 students with limited speech, 91 (71\%) had access to at least one of 44 aided AAC systems that were shared across students in 19 of the 26 classrooms. Of these 44 systems, $17(39 \%)$ were nonelectronic and $27(61 \%)$ were electronic. A total of 47 students (36\% of the 130) had access to both personal and shared aided AAC systems. Regarding symbols used on the aided AAC, only two personal systems (nonelectronic alphabet boards) used orthography exclusively, while two other personal devices (SGDs) allowed for both graphic symbol-based communication and text generation via an onscreen keyboard. All other aided AAC displayed 
graphic symbols or photographs, mostly in combination with a gloss. A total of 25 students with limited speech (19\% of the 130) from the included preschool and Foundation phase classrooms did not have access to any type of aided AAC for expression.

Teachers' perceptions regarding the implementation of aided AAC. Quantitative data were collected regarding teachers' perceptions about (a) the usefulness of aided AAC for various purposes, (b) their own roles in supporting students using aided AAC (see Figure 1), (c) the challenges they experienced in this process (see Figure 2), (d) the extent to which other team members provided them with support, (e) their competence in supporting students using aided AAC, and (f) further training needs. On a 5-point rating scale ranging from 0 (not useful at all) to 4 (very useful), teachers, on average, rated the usefulness of aided AAC highest for supporting learning $(M=3.3)$ and least useful for supporting communication with peers $(M=0.8)$. The usefulness of aided AAC to support classroom communication received an average rating of 2.5. 


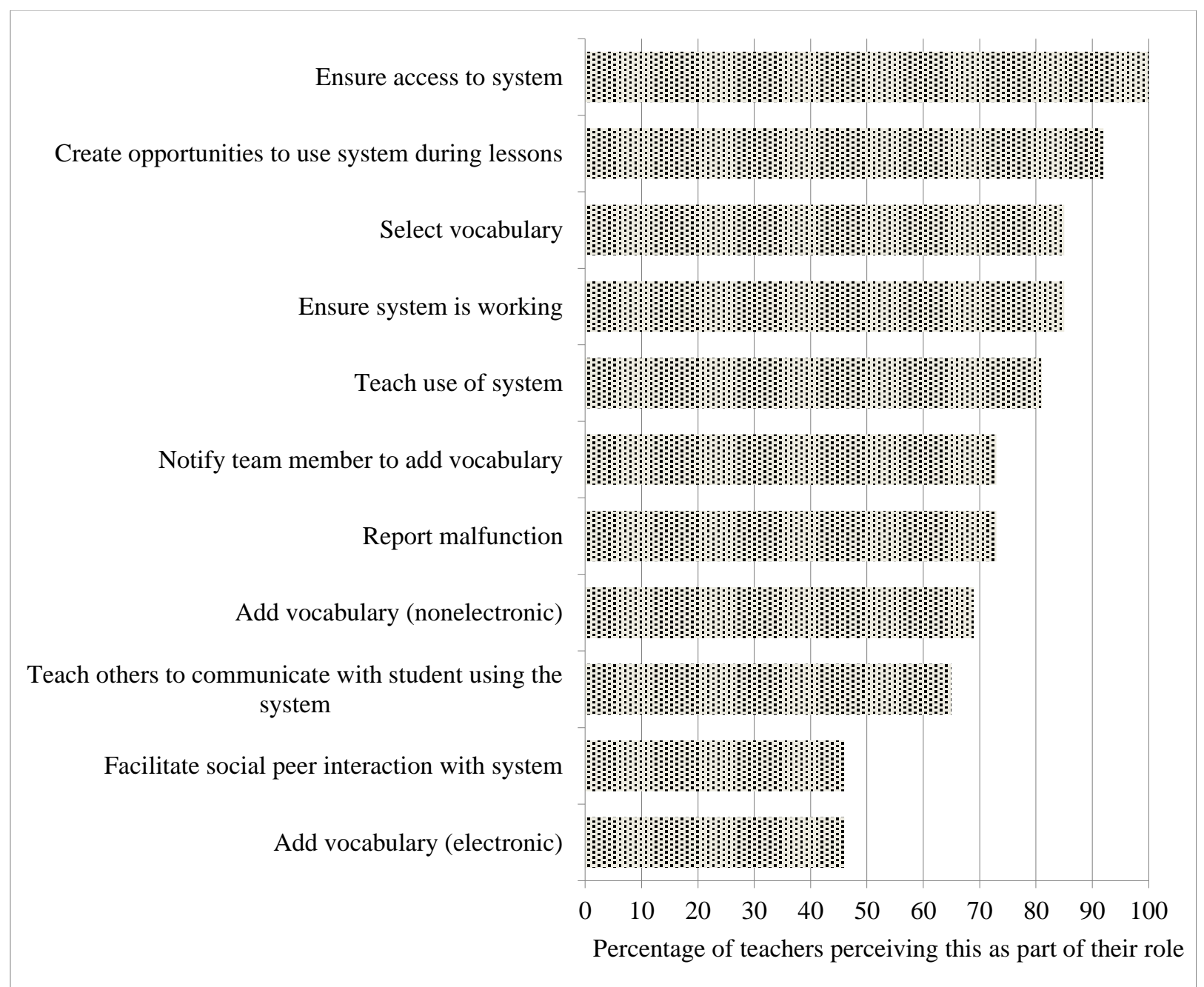

Figure 1. Teachers' perceptions of their roles in supporting students using aided AAC. 


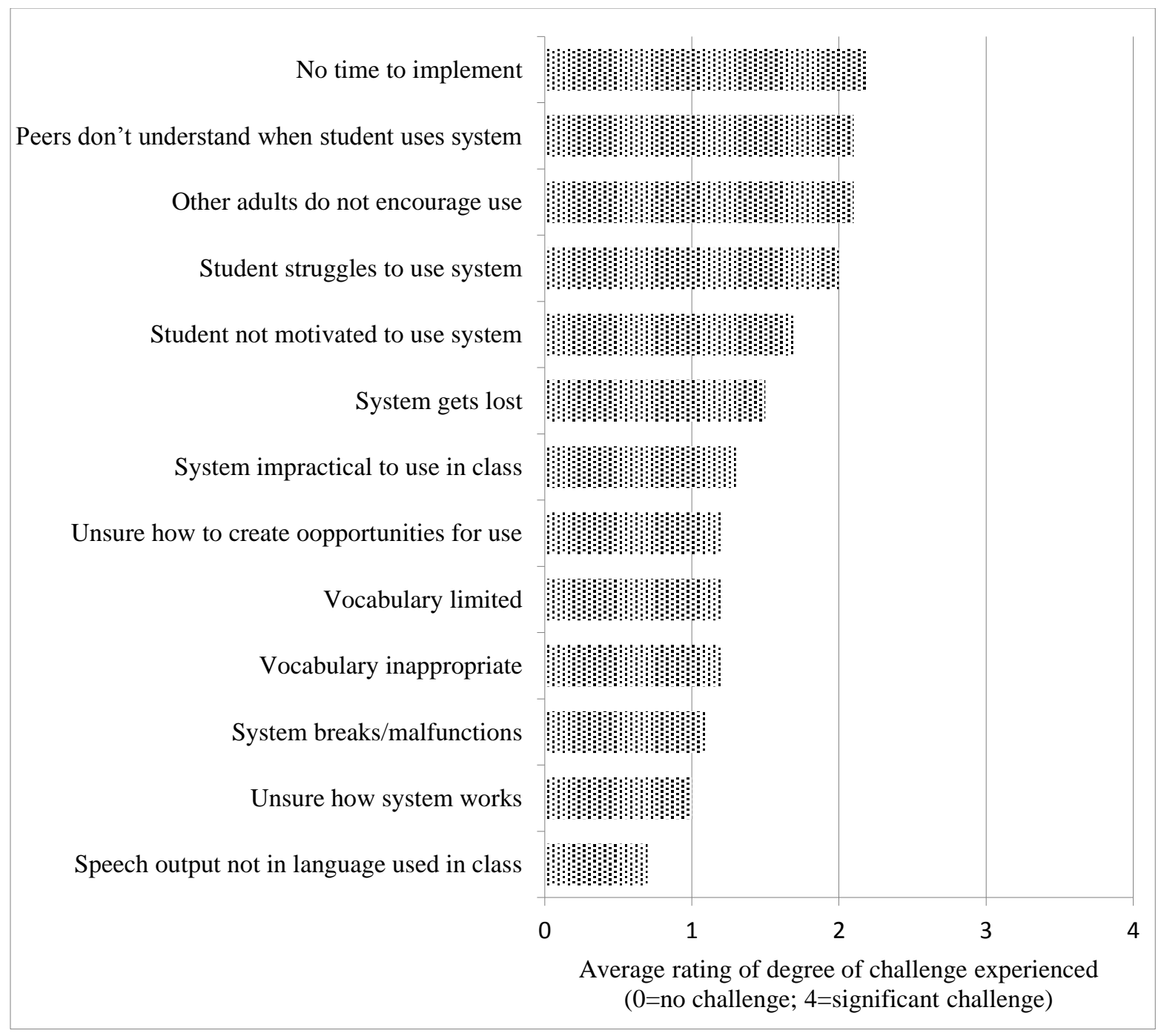

Figure 2. Teachers' perceptions of challenges experienced in supporting students who use aided AAC.

Teachers perceived their role in supporting students using aided AAC in the classroom to encompass a variety of tasks (see Figure 1). All felt that ensuring student access to aided AAC was part of their role, and most $(n=26,92 \%)$ felt that teaching in a way that created opportunities for students to use aided AAC for expression was another aspect of their role. Less than half $(n=12,46 \%)$ felt that adding vocabulary to electronic aided AAC or facilitating the student's social interaction with peers using aided AAC was part of their role.

Teachers experienced a variety of challenges in supporting students who use aided AAC 
(see Figure 2). They rated lack of time for implementation as the most significant, assigning this factor an average rating of 2.2 on a 5-point scale ranging from 0 (no challenge) to 4 (significant challenge). Factors related to communication partners (peers' lack of understanding and the fact that other adults did not encourage the use of the aid) were also perceived as quite challenging ( $M=2.1$ for each of these factors). Challenges suggesting a poor match between student needs and abilities and the aided AAC provided received average ratings of 2.0 (student struggles to use the aid) and 1.7 (lack of motivation to use the aid). Factors related to the aided AAC systems themselves (malfunctioning, limited vocabulary, tendency to get lost, etc.) were found less challenging overall (average ratings ranged from 1.5 to 0.7 ), while challenges related to teacher knowledge and skill (creating opportunities for use of and knowledge about the functioning of the aid) were also perceived as less severe (average ratings of 1.2 and 1.0, respectively).

All schools had occupational therapists employed through the education department and based at the school, while six of the eight schools had SLPs - three of 26 teachers therefore did not have an SLP as a possible team member. Most teachers $(n=24)$ had full-time or part-time classroom assistants helping in class. Classroom assistants typically have no or minimal training and are employed by the school to assist the teacher in a variety of ways, including personal care of students. SLPs were perceived to provide the most support in aided-AAC implementation, with an average rating of 3.2 on a 5-point scale ranging from 0 (no support) to 4 (a lot of support $)$, followed by classroom assistants $(M=2.5)$ and OTs $(M=1.8)$. Parents were perceived to provide the least amount of support $(M=1.1)$

Teachers rated their own competence in supporting students using aided AAC on a 5point scale ranging from 0 (not at all competent) to 4 (completely competent). Teacher's ratings ranged from 1 to 4 , with a mean of $2.5(S D=.6)$. No teacher felt a complete lack of competence. 
Almost all of the teachers (92\%) wanted further training.

\section{Qualitative Data}

All teachers provided at least one text segment for coding in response to the six questions. Overall, 182 text segments were coded. Four text segments could not be assigned a code: three segments were not related to implementation of aided AAC and the meaning of one segment was difficult to interpret. Of the remaining 178 coded text segments, 174 fell into five themes. Four segments did not relate to any of these themes and were not further analyzed. The five themes were (a) Teacher-related factors, (b) Classroom context, (c) Aided AAC, (d) Students' abilities and behavior, and (e) Other role players. Table 1 provides an overview of the themes and subthemes, as well as examples of issues discussed by participants under each subtheme.

Of the coded text segments, 59 addressed teacher-related factors. Eleven teachers wrote about their lack of competence, confidence, experience, and training, using words like “difficult," "challenge," and "unsure." However, 11 teachers wrote about their openness and willingness to learn and also reported on feeling competent and confident regarding various aspects of aided AAC (facilitators). Over half of the teachers mentioned their need for additional training.

There were nine text segments related to the classroom context. Barriers included the size of the class, diverse student abilities, and lack of time available for AAC implementation in classrooms described as "busy." In contrast, one teacher described her small class as a facilitator to aided AAC implementation. Teachers suggested that redesigned classroom spaces and smaller, more homogenous classes would benefit AAC implementation.

There were 52 text segments related to aided AAC. Barriers included breakage, 
Table 1 Themes, Subthemes, and Examples of Issues Mentioned by Participants

\begin{tabular}{|c|c|c|c|c|}
\hline Theme & Subtheme & No of statements & No of teachers & Examples of issues mentioned \\
\hline \multirow[t]{3}{*}{ Teacher-related factors } & Barriers & 14 & 11 & $\begin{array}{l}\text { Lack of experience } \\
\text { Lack of knowledge regarding aided-AAC implementation } \\
\text { Feeling incompetent/unsure in device implementation } \\
\text { Lack of training }\end{array}$ \\
\hline & Facilitators & 18 & 11 & $\begin{array}{l}\text { Teacher openness/willingness to learn } \\
\text { Teacher competence and confidence }\end{array}$ \\
\hline & $\begin{array}{l}\text { Proposed solutions and support } \\
\text { needs }\end{array}$ & 27 & 16 & $\begin{array}{l}\text { Clarity on expectations and feedback on performance } \\
\text { Experience } \\
\text { Training on various aspects of aided-AAC implementation }\end{array}$ \\
\hline \multirow[t]{3}{*}{ Classroom context } & Barriers & 5 & 5 & $\begin{array}{l}\text { Size of class } \\
\text { Lack of time available for AAC implementation } \\
\text { Other demands on teachers }\end{array}$ \\
\hline & Facilitators & 1 & 1 & Small class \\
\hline & $\begin{array}{l}\text { Proposed solutions and support } \\
\text { needs }\end{array}$ & 3 & 3 & $\begin{array}{l}\text { Redesigned classroom space } \\
\text { Smaller more homogenous classes }\end{array}$ \\
\hline \multirow[t]{5}{*}{ Aided AAC } & Barriers & 12 & 8 & $\begin{array}{l}\text { Breakage/malfunctioning } \\
\text { Not matched to student abilities/needs } \\
\text { Time-consuming to make/implement }\end{array}$ \\
\hline & Facilitators & 2 & 2 & $\begin{array}{l}\text { Availability } \\
\text { Adaptations to suit different contexts }\end{array}$ \\
\hline & $\begin{array}{l}\text { Proposed solutions and support } \\
\text { needs }\end{array}$ & 9 & 8 & $\begin{array}{l}\text { Obtaining aided AAC better matched to student abilities } \\
\text { Availability of aided AAC for teachers to familiarize themselves with }\end{array}$ \\
\hline & Benefits & 8 & 7 & For children and partners \\
\hline & $\begin{array}{l}\text { Contrast: Other modes of } \\
\text { communication }\end{array}$ & 17 & 13 & $\begin{array}{l}\text { Situations in which other modes are used } \\
\text { Benefits and drawbacks of other modes }\end{array}$ \\
\hline \multirow[t]{3}{*}{ Other team members } & Barriers & 10 & 6 & $\begin{array}{l}\text { Lack of peer interaction/socialization } \\
\text { Lack of human resources (e.g., no SLP or classroom assistant) } \\
\text { Lack of parent involvement/support for implementation }\end{array}$ \\
\hline & Facilitators & 10 & 10 & Support from classroom assistants and personal facilitators, parents and SLPs \\
\hline & $\begin{array}{l}\text { Possible solutions/support } \\
\text { needs }\end{array}$ & 19 & 14 & $\begin{array}{l}\text { Human resources (e.g., classroom assistant, person dedicated to constructing aided AAC } \\
\text { systems) } \\
\text { Support from parents, SLPs, } \\
\text { Training peers, parents, and classroom assistants }\end{array}$ \\
\hline \multirow[t]{3}{*}{ Students' characteristics } & Barriers & 10 & 7 & $\begin{array}{l}\text { Multiple disabilities } \\
\text { Student's use of AAC system is not purposeful }\end{array}$ \\
\hline & Considerations & 3 & 3 & Require time to learn to use aided $\mathrm{AAC}$ \\
\hline & $\begin{array}{l}\text { Possible solutions and support } \\
\text { needs }\end{array}$ & 2 & 2 & Therapy and training \\
\hline
\end{tabular}


malfunctioning, and the perception that the aided AAC system was not matched to students' abilities. Teachers also commented on the time required to make nonelectronic aided AAC (e.g., "It takes time to print, laminate and Velcro pictures..." [Teacher 13]), and the slow rate of interaction typical of aided AAC. Eight teachers felt that access to different or more diverse aided AAC options was necessary to address some of the barriers they were experiencing. They mentioned multisensory (i.e., not only visual but also tactile) aided AAC that was simpler to use and aided AAC that offered speech output. Seven teachers commented on the benefits of aided AAC for students and partners, while four observed that aided AAC was typically implemented in specific classroom situations. A further 17 text segments contrasted aided AAC with other modes of communication, and included explanations of why other modes were sometimes preferred.

There were 39 text segments related to other team members. Of these there were 10 text segments that described barriers (e.g., limited interactions between students using AAC and peers, lack of parental support, and lack of human resources) and another 10 that described facilitators (e.g., support from parents, classroom assistants, and SLPs). Additional human resources; increased support from parents and SLPs; and training of peers, parents, and classroom assistants were some of the possible solutions and support needs that teachers identified under this theme.

There were 15 text segments related to students' characteristics. Seven teachers wrote about barriers, such as multiple disabilities, that, in their opinion, made the implementation of aided AAC difficult. Three text segments highlighted the need to take student characteristics into consideration when implementing aided AAC (e.g., acknowledging that it may take students a long time to learn to use aided AAC). Only two teachers felt that changing students' 
characteristics (specifically, skill) through therapy and training conducted outside of the classroom would solve some of the implementation barriers.

\section{Discussion}

Assisting students with limited speech to communicate as effectively as possible, thereby ensuring maximum classroom participation, is a complex task that is influenced by multiple factors and involves multiple team members and systems (De Bortoli et al., 2011; De Bortoli, Arthur-Kelly, Mathisen, \& Balandin, 2014; Naraian, 2010). Provision and implementation of aided AAC in classrooms may enable students to take an active part in the academic and social dimensions of classroom life.

\section{Provision and Implementation of Aided AAC in Special Schools}

Of the 22 schools targeted during recruitment that accommodated students with limited speech, $20(91 \%)$ had some form of aided AAC system within the school. About 17 years prior to this study, Alant (1999) found that, in 19 schools for students with severe intellectual disability (from a metropolitan area partially overlapping with the one in which the current schools fell), less than $1 \%$ of the students with limited speech had access to any form of aided AAC. Increased awareness, teacher training, and national DoE policy mandates for provision (DoE, 2007, 2010) may have contributed to an increase in provision. However, the schools included were from urban districts of the wealthiest province in the country, within reasonable distance from assistive technology providers and an AAC specialist center. Provision of aided AAC in other special schools in South Africa is likely more limited.

Of the aided AAC systems that were assigned exclusively to one student (personal systems) used in preschool and/or Foundation phase classrooms, most were nonelectronic. Electronic systems were more commonly shared between students. Funding through the national 
DoE remains limited (Donohue \& Bornman, 2014), and the same documents that mandate provision of aided AAC (DoE, 2007, 2010) are conspicuously silent about funding provisions. When schools procure more expensive electronic aided AAC, it seems that these systems are then shared across multiple students, possibly to spread the benefit wider. Only some of students' personal aided AAC systems were sent home or were available in duplicate at home. The lack of teamwork between school staff and families revealed in both quantitative and qualitative data may underlie this practice: It may be that if school staff believed that parents would not implement aided AAC at home, they kept the equipment at school. Fear of theft of or damage to electronic systems (occurring, for example, while students travel on public transport to and from school) is a typical reason why electronic aided AAC devices procured by the school (and regarded as the property and responsibility of the school) remain at school, and this is common practice in South African special schools (N. Maré, personal communication, September 1, 2016).

Provision of aided AAC to schools does not translate automatically into implementation of aided communication for the purpose of supporting expression. Less than half of the schools that possessed aided AAC implemented it to support expression for students with limited speech in the preschool and/or Foundation phase classrooms. Similarly, 19\% of preschool and Foundation students with limited speech from the participating eight schools did not have access to any form of aided AAC for expression. Intervention teams may purposefully choose to focus on unaided AAC only. Manual sign, for example, effectively supports various communication outcomes for students who have limited speech but who have adequate motor skills to produce the signs (Gevarter et al., 2013; Schlosser \& Sigafoos, 2006). In other instances, particularly where motor control is limited, aided AAC systems may be required, yet not implemented as the 
result of various barriers.

\section{Teacher Perceptions Regarding Implementation of Aided AAC}

From the quantitative and qualitative data gathered, a complex array of factors was perceived by teachers as influencing the implementation of aided AAC to facilitate expression and participation of students with limited speech in classrooms. To integrate the data into a comprehensive picture, both quantitative and qualitative data were incorporated into the five qualitative themes identified (see Table 1).

Teacher-related factors. These included teachers' perceptions of their role, their competence, confidence, and training. Teachers viewed their role as comprehensive in supporting students using aided AAC. For example, many teachers felt that selecting and adding vocabulary to nonelectronic aided AAC was part of their role. Vocabulary selection is one of the most challenging aspects of designing and customizing aided AAC (Banajee, Dicarlo, \& Buras Stricklin, 2003) and teachers' involvement in this process suggests a high level of ownership in not only implementation but also customization. In contrast, Kent-Walsh and Light (2003) found that general education teachers tended to lack ownership of the process of implementing aided-AAC with students in their classes, and relied on educational assistants to address any operational issues. Lack of availability of or support from other team members may have led teachers in the current study to take up more of the tasks that otherwise may have been spread across different team members. Many teachers felt that teaching the use of aided AAC was their role, echoing best practice recommendations that AAC training needs to take place in classroom contexts rather than in isolation and should form an integral part of the curriculum (Calculator \& Black, 2009; Soto, 1997). While nearly all teachers felt that creating opportunities for aided AAC use during lessons was part of their role, less than half felt that they should also encourage 
its use to promote social peer interaction. This may explain the perceived lack of motivation on the part of some students to use aided AAC.

Teachers felt relatively competent in supporting students using aided AAC. Similarly, when rating different challenges associated with the implementation of aided AAC, the two related to their own skills ("Unsure how to create opportunities for system use" and "Unsure how the system works") were regarded overall as minimal to somewhat challenging. Teacher selfefficacy (i.e., their "beliefs in their own abilities to plan, organize, and carry out activities required to attain given educational goals" [Skaalvik \& Skaalvik, 2007, p. 612]) has been positively correlated not only with higher student achievement but also with increased use of particular teaching strategies, positive attitudes towards change and challenges, teachers' goals and plans, and a higher willingness to teach "difficult students," including those with disabilities (Skaalvik \& Skaalvik, 2007, p. 611). Qualitative written comments from seven teachers indicated their willingness to learn, while four commented on their feelings of confidence and competence regarding implementation of aided AAC.

At the same time, feelings of competence were not uniform across teachers or different aspects of implementation (e.g., implementation of electronic versus nonelectronic aided AAC). Similar perceptions regarding lack of competence in communicating with and educating students with limited speech were reported for teachers in inclusive and special school settings (Dada \& Alant, 2001; De Bortoli et al., 2011; Kent-Walsh \& Light, 2003). Almost all teachers in the current study felt they would benefit from additional training, which can heighten self-efficacy when the skill being trained is perceived as learnable (Gist \& Mitchell, 1992). Vicarious experiences (e.g., watching a successful model of a particular skill) also offer the potential to heighten self-efficacy (Pasupathy \& Bogschutz, 2013). Although some teachers indicated that 
they wanted lectures and formal training, they most frequently suggested that training should take place within their own classrooms. Teacher 8 wrote, for example, that she wanted a “competent model/trainer ... [who] can implement practically and demonstrate the use [of aided AAC] with my children in my class." Due to the complex and highly individual nature of implementing aided AAC, teachers may need in-situ support and modeling of appropriate practices in their classrooms (De Bortoli et al., 2011).

Classroom context. Teachers cited lack of time for implementing aided AAC in classrooms as the greatest challenge, rating this aspect slightly over the middle of the 5-point scale. Classrooms are complex environments with various demands and expectations placed on teachers, who are expected to effectively instruct students, manage and organize their classrooms, and provide emotional support to students (Schmitt \& Justice, 2011).

Across the group, the concern that aided AAC was impractical to use in the classroom setting was rated as minimally to somewhat challenging. Qualitative data highlighted class size and diversity of student abilities as barriers. The average teacher to student ratio of 1:11 (range: 1:5 to $1: 18$ ) across the 26 classrooms in the current study may be regarded as high, given the high support needs of students. In an Australian study focused on children with multiple and severe disabilities, De Bortoli et al. (2011) reported that teachers found that a teacher-to-student ratio of 1:6 was too high to adequately meet students' communication needs, and that a ratio of 1:2 adults to students was more realistic. Certainly staffing provision in the South African education system remains challenging (DoE, 2006).

Aided AAC. Overall, issues such as breakage, malfunctioning, getting lost, and limited or inappropriate vocabulary were perceived as minimally to somewhat challenging. Using aided $\mathrm{AAC}$, and graphic symbol-based aided AAC in particular, brings with it certain challenges that 
are not experienced when using spoken communication and other unaided methods such as keyword signing (Gevarter et al, 2013; Smith, 2006; Wilkinson \& Hennig, 2007). Although some challenges can be reduced by appropriate design (e.g., "just-in-time” programming capabilities; Schlosser et al., 2016); continuous customization; and ensuring a good fit between the person, the system, and the environment, many of these challenges remain inherent to graphic symbolbased aided AAC (Smith, 2006). Limited vocabulary may lead to aided AAC being implemented primarily in specific structured contexts. Contexts mentioned by the teachers in this study included song time, morning ring, reciting nursery rhymes, and answering questions. Teachers also spoke about unaided forms of communication and situations in which these were preferred (e.g., for peer interactions). Aided AAC typically forms part of a multimodal communication repertoire, and its implementation is often situation-specific (Smith \& Connolly, 2008; McCord \& Soto, 2004).

Operational demands of aided AAC may not always be well matched to students' abilities (Naraian, 2010). Because the study focused on implementation of aided AAC in the classroom, information about the way in which students were assessed for aided AAC was not obtained. Whether assessments led to the provision of appropriate aided AAC is therefore unknown, and teachers merely judged the goodness of fit between students and aided AAC in a limited way (e.g. rating appropriateness of vocabulary, student motivation to use aid, etc.). Quantitatively, teachers rated the usefulness of aided AAC to support learning to be high, suggesting that they acknowledged the centrality of communication in the learning process.

Other team members. Peers. On average, teachers rated peers' inability to understand communication via the use of aided AAC as the second-biggest challenge experienced, and also indicated that peer interactions were limited, and/or occurred mainly through informal unaided 
modes. Less than half of the teachers perceived the facilitation of social interactions via aided AAC as part of their role. Teachers may underestimate the importance of peer interactions in learning (Mashburn, Justice, Downer, \& Pianta, 2009) or believe that the use of unaided forms is sufficient for this purpose. Limited peer interaction between children using AAC has been reported in both special education classrooms (De Bortoli et al., 2011) and inclusive classrooms (Kent-Walsh \& Light, 2003). Peer training, as proposed by some teachers in this study, is a strategy that can lead to increased peer interaction (Lilienfeld \& Alant, 2005).

SLPs and OTs. Teachers saw SLPs as the team members most supportive of the implementation of aided AAC in the classroom. As communication and language interventionists, SLPs typically play a lead role in AAC intervention (Calculator, 2009; Hunt et al., 2002). The absence of SLPs from school staff was mentioned as a barrier: three teachers did not have an SLP on their school staff contingent. This is not unusual, given that the reported SLP to population ratio in South Africa is 1:25 000 (Kathard \& Pillay, 2013). Occupational therapists were employed at all eight participating schools. Teachers experienced them as less supportive than SLPs according to the quantitative rating. The OTs typically play a role in the implementation of aided AAC for students with physical disabilities, for example, addressing seating and positioning aspects and assisting with optimal physical access to the aid (Beukelman \& Mirenda, 2013). At the same time, OTs may become involved in AAC implementation more comprehensively, especially in the absence of SLPs (Cameron \& Markowicz, 2009).

Parents. A perceived lack of parent involvement was reflected in both the quantitative and the qualitative data. Family-centered, collaborative practice has been highlighted as a cornerstone of successful AAC intervention (Alant, 2005; Calculator \& Black, 2009; Hunt et al., 2002), and a lack of parental involvement can lead to discrepancies in priorities regarding AAC 
intervention, and a poor fit between the aided AAC and the family's interaction patterns and life style (Goldbart \& Marshall, 2004; Naraian, 2010; Pickl, 2011). Of the eight schools included in this study, four offered residential facilities to students. While it was beyond the scope of the study to determine how many of the students using AAC lived in residence, this factor may have influenced collaboration with parents, as contact between parents and schools would likely have been less frequent when the students did not live at home. Lack of effective collaboration with parents has been reported in numerous studies as a concern expressed by teachers (e.g., KentWalsh \& Light, 2003; Pickl, 2011), SLPs (e.g., De Bortoli et al., 2014) and parents (e.g., McNaughton et al., 2008). Various factors may influence this collaboration, such as role expectations, openness, and willingness on behalf of teachers and parents to collaborate; as well as teachers' openness to and understanding of multicultural and multilingual issues (McNaughton et al., 2008; Pickl, 2011). None of the teachers mentioned these last factors as barriers to implementation of AAC, although all of their classes were linguistically and culturally diverse. According to Bauce (2014), cultural competence includes the awareness of cultural influences on intervention practices and preferences. Previous studies have confirmed that a lack of cultural awareness on the part of teachers and other service providers negatively influences collaboration with families in AAC implementation (McCord \& Soto, 2004; Pickl, 2011). A special education model of the service provider as the expert (Kalyanpur, Harry, \& Skritic, 2000) and historical inequalities and power imbalances under colonial and Apartheid regimes (Pillay \& Kathard, 2015) may further contribute towards a lack of equal partnership between parents and school staff, and negatively influence parent involvement.

Classroom assistants and personal facilitators. Teachers rated classroom assistants as the second-most supportive team members. Some teachers felt that additional human resources 
were needed in classrooms for making nonelectronic aided AAC and implementing aided AAC in general, or highlighted the lack of classroom assistants as a barrier. Teachers also felt that training classroom assistants in the implementation of aided AAC was needed. In addition, two teachers mentioned the positive role of personal facilitators who supported implementation of aided AAC for specific students in class. Unlike classroom assistants, personal facilitators are typically employed by parents and accompany one specific student to school, assisting this student in a variety of ways. The pivotal role of educational assistants or teacher aides in AAC implementation and education of students with limited speech has been noted in other studies (De Bortoli et al., 2011; Kent-Walsh \& Light, 2003).

Students' characteristics. Challenges related to students' skill and motivation in using aided AAC received ratings of 2.0 and 1.7, respectively. It must be acknowledged that interpretations of these challenges are likely the result of a poor match between student needs and abilities and the aided AAC provided. While 10 teachers wrote about barriers related to students' characteristics (their body functions, such as intellectual abilities, as well as personal factors such as motivation), addressing students' characteristics directly in intervention was not seen as a general solution to facilitate AAC implementation. Teachers seem to acknowledge that students' intrinsic characteristics (i.e., body functions and structures, personal factors) may be quite stable and resistant to change. Focusing exclusively on these aspects reflects a deficitbased approach, situating the problem explanation within the individual rather than within the environment (Raghavendra et al., 2007; Van Niekerk \& Tönsing, 2015; WHO, 2001).

\section{Summary}

This study provided an initial exploration of the implementation of aided AAC to facilitate expressive communication for students with limited speech in a number of South 
African special schools. Although provision of aided AAC in the school districts targeted seems to have somewhat improved over the last 15-20 years, limitations still exist, both in provision and implementation. Teachers who had experience supporting students who used aided AAC identified various factors (grouped into five themes) that influenced the extent of implementation of aided communication, namely those related to themselves, the classroom context, aided AAC, other team members, and students who used aided AAC.

On the one hand, the five themes identified in this study may represent generic areas that need consideration in aided AAC implementation within classrooms, regardless of context. As is evident throughout the discussion, many of the barriers and facilitators identified by teachers resonate with findings from other studies conducted in economically developed countries such as the United States of America, Austria and Israel (De Bortoli, Arthur-Kelly, Foreman, Balandin, \& Mathisen, 2011; Kent-Walsh \& Light, 2003; Patel \& Khamis-Dakwar, 2005; Pickl, 2011). The five themes also articulate with the components and domains of the ICF (WHO, 2001), as four themes describe environmental factors (teacher-related factors, the classroom context, aided AAC and other role players), while one theme (student characteristics) incorporates both body functions and personal factors (WHO, 2001). While the specific environmental facilitators and barriers may differ from context to context, the five broad themes identified in this study may be useful to guide the focus of both intervention and further research in implementation of aided AAC across classroom contexts. Furthermore, the strong focus of teachers in the current study on environmental rather than student-intrinsic barriers, facilitators, and solutions highlights the crucial role of the environment in determining functioning, and confirms the usefulness of the ICF framework in practice.

On the other hand, the findings need to be understood and interpreted within the context 
of South Africa's education system and also within a developing country context. Despite progressive disability policies, many developing countries face severe challenges in implementation related to persistent historical inequalities, limitations in human and financial resources, and neo-liberal macro-economic policies that compete with and often supersede social policies (McEwan \& Butler, 2007). In relation to assistive technology (including aided AAC), these challenges manifest in the form of limited provision, limited human resources to support implementation, and limited training of team members, as evidenced in this study and others from developing county contexts (Borg, Larsson, \& Östergren, 2011; Mukhopadhyay \& Nwaogu, 2009; Wormnaes \& Malek, 2004). South African education policy mandates appropriate aided AAC provision, implementation, effectiveness monitoring, and teacher training, yet specific implementation plans (including timelines and funding provisions) are not stipulated in national policies. Decisions about how to interpret and apply the policies are often enacted at the level of the school or school district, and there are no central procedures for policy enforcement (Donohue \& Bornman, 2014). Clear directives regarding policy implementation plans, national funding allocation with transparent mechanisms for accessing this funding and central monitoring of compliance with policies are urgently needed, in order to ensure meaningful provision and implementation of aided AAC to support participation and learning of students with limited speech in classrooms, leading to meaningful and positive long-term outcomes.

\section{Limitations and Suggestions for Further Research}

The small number of participants in the study limits the generalizability of results.

Teachers were all teaching at urban schools in the most resourced province in South Africa, and their experiences and perceptions may not be reflective of all teachers teaching students using 
aided AAC in South Africa. At the same time, the likelihood that aided AAC would be implemented to a greater extent in less resourced education settings is probably small. In addition, the presence of the researcher during completion of the survey, although helpful to assist teachers in clarifying terminology, compromised teachers' anonymity and may have led them to answer in what they perceived as socially desirable ways.

While the results from the study give an initial perspective on the implementation of aided AAC in these special schools and teachers' perceptions of this process, various factors require further investigation. The ICF framework (WHO, 2001) may prove a useful tool for identifying additional factors both at a classroom level and within the broader geo-political and socio-cultural context that may affect the implementation of aided AAC and ultimately, student participation, learning, and long-term outcomes. At the classroom level and within the school context, for example, it will be important to acquire a better understanding of (a) assessment practices of students in need of AAC and the decision-making process preceding procurement of aided AAC, (b) classroom implementation practices, and (c) team collaboration at special schools. Such data may be obtained both through direct observation and interviewing/surveying other team members. Understanding teachers' (and other team members') underlying beliefs about or attitudes towards aided AAC and related factors (e.g., student potential, collaboration, etc.) may help to explain some of their practices and also perceptions. A better understanding of barriers and facilitators at a national policy level will situate provision and implementation of aided AAC in schools within the broader South African education context. Further research is also needed to determine how intervention programs can systemically address the multitude and complexity of factors influencing implementation of aided AAC in classrooms. Interventions at classroom level and also at a broader policy level would be relevant. Ultimately, researchers and 
service providers may start to better define intervention practices that are appropriate and effective within the South African context to optimize communication and participation of students who rely on aided AAC in classrooms.

\section{References}

Alant, E. (1999). Students with little or no functional speech in schools for students with severe mental retardation in South Africa. Augmentative \& Alternative Communication, 15, 83-94.

Alant, E. (2005). Support-based AAC intervention. In E. Alant \& L. L. Lloyd (Eds.), Augmentative and alternative communication and severe disabilities: Beyond poverty (pp. 155-191). London, United Kingdom: Whurr.

American Speech-Language Hearing Association (2015). Augmentative and alternative communication. Retrieved from http://www.asha.org/public/speech/disorders/AAC/

Banajee, M., Dicarlo, C., \& Buras Stricklin, S. (2003). Core vocabulary determination for toddlers. Augmentative and Alternative Communication, 19, 67-73. doi:10.1080/0743461031000112034

Bauce, K. (2014). Cultural competence model. In J.J Fitzpatrick, \& G. McCarthy (Eds.), Theories guiding nursing research and practice (pp. 159-171). New York, NY: Springer.

Beukelman, D. R., \& Mirenda, P. (2013). Augmentative and alternative communication: supporting children and adults with complex communication needs (4th ed.). Baltimore, MD: Paul H. Brookes.

Borg, J., Larsson, S., \& Östergren, P.-O. (2011). The right to assistive technology: for whom, for what, and by whom? Disability and Society, 26, 151-167. doi:10.1080/09687599.2011.543862 
Calculator, S. N. (2009). Augmentative and alternative communication (AAC) and inclusive education for students with the most severe disabilities. International Journal of Inclusive Education, 13, 93-113. doi:10.1080/13603110701284656

Calculator, S. N., \& Black, T. (2009). Validation of an inventory of best practices in the provision of augmentative and alternative communication services to students with severe disabilities in general education classrooms. American Journal of Speech-Language Pathology, 18, 329-343.

Cameron, D., \& Markowicz, L. (2009). Augmentative and alternative communication: International perspectives. Occupational Therapy Now, 11, 12-14.

Clarke, M., Mcconachie, H., \& Price, K. (2001). Speech and language therapy provision for children using augmentative and alternative communication systems. European Journal of Special Needs Education, 16, 41-54. doi:10.1080/08856250150501798

Dada, S., \& Alant, E. (2001). Teachers' attitudes towards learners with little or no functional speech using augmentative/alternative communication devices. South African Journal of Education, 21, 99-103.

Dada, S., \& Alant, E. (2002). A comparative study of the attitudes of teachers at special and educationally inclusive schools towards learners with little or no functional speech using communication devices. South African Journal of Education, 23, 213-218.

De Bortoli, T., Arthur-Kelly, M., Foreman, P., Balandin, S., \& Mathisen, B. (2011). Complex contextual influences on the communicative interactions of students with multiple and severe disabilities. International Journal of Speech-Language Pathology, 13, 422-435. doi: $10.3109 / 17549507.2011 .550691$

De Bortoli, T., Arthur-Kelly, M., Mathisen, B., \& Balandin, S. (2014). Speech-language 
pathologists' perceptions of implementing communication intervention with students with multiple and severe disabilities. Augmentative and Alternative Communication, 30, 55-70. doi:10.3109/07434618.2014.881916

Department of Basic Education (2016). School fees and exemption. Retrieved from http://www.education.gov.za/Informationfor/ParentsandGuardians/NoFeeSchools.aspx

Department of Education (2001). Education White Paper 6 on special needs education: building an inclusive education and training system. Pretoria, South Africa: Author

Department of Education (2006). The national policy framework for teacher education and development in South Africa. Pretoria, South Africa: Author.

Department of Education (2007). Guidelines to ensure quality education and support in special schools and special school resource centres. Pretoria, South Africa: Author.

Department of Education (2010). Guidelines for full-service/inclusive schools. Pretoria, South Africa: Author.

Department of Education (2015). Report on the implementation of Education White Paper 6 on inclusive education. Pretoria, South Africa: Author.

Donohue, D., \& Bornman, J. (2014). The challenges of realising inclusive education in South Africa. South African Journal of Education, 34(2), 1-14.

Gevarter, C., O’Reilly, M. F., Rojeski, L., Sammarco, N., Lang, R., Lancioni, G. E., \& Sigafoos, J. (2013). Comparing communication systems for individuals with developmental disabilities: A review of single-case research studies. Research in Developmental Disabilities, 34, 4415-4432. doi:10.1016/j.ridd.2013.09.017

Gist, M. E., \& Mitchell, T. R. (1992). Self-efficacy: A theoretical analysis of its determinants and malleability. Academy of Management, 17, 183-211. 
Goldbart, J., \& Marshall, J. (2004). "Pushes and pulls" on the parents of children who use AAC. Augmentative and Alternative Communication, 20, 194-208. doi:10.1080/07434610400010960

Human Rights Watch (2015). “Complicit in Exclusion.” South Africa's failure to guarantee an inclusive education for children with disabilities. Retrieved from https://www.hrw.org/report/2015/08/18/complicit-exclusion/south-africas-failure-guaranteeinclusive-education-children

Hunt, P., Soto, G., Maier, J., Müller, E., \& Goetz, L. (2002). Collaborative teaming to support students with augmentative and alternative communication needs in general education classrooms. Augmentative and Alternative Communication, 18, 20-35.

Kalyanpur, M., Harry, B., \& Skrtic, T. (2000). Equity and advocacy expectations of culturally diverse families' participation in special education. International Journal of Disability, Development and Education, 47, 119-136. doi:10.1080/713671106

Kathard, H., Pascoe, M., Ramma, L., Jordaan, H., Moonsamy, S., Wium, A.-M., ... Khan, N. (2011). How can speech-language therapists and audiologists enhance language and literacy outcomes in South Africa? (And why we urgently need to). South African Journal of Communication Disorders, 58, 59-71.

Kathard, H., \& Pillay, M. (2013). Promoting change through political consciousness: a South African speech-language pathology response to the World Report on Disability. International Journal of Speech-Language Pathology, 15, 84-89. doi:10.3109/17549507.2012.757803

Kathard, H., \& Pillay, M. (2015). A study of teacher-learner interactions: A continuum between monologic and dialogic interactions. Language, Speech, and Hearing Services in Schools, 
46, 222-241. doi:10.1044/2015

Kent-Walsh, J., \& Light, J. (2003). General education teachers' experiences with inclusion of students who use augmentative and alternative communication. Augmentative and Alternative Communication, 19, 104-124. doi:10.1080/0743461031000112043

Lilienfeld, M. S., \& Alant, E. (2005). The social interaction of an adolescent who uses AAC: The evaluation of a peer training programme. Augmentative and Alternative Communication, 21, 278-294. doi:10.1080/07434610500103467

Mashburn, A. J., Justice, L. M., Downer, J. T., \& Pianta, R. C. (2009). Peer effects on children's language achievement during pre-kindergarten. Child Development, 80, 686-702. doi:10.1111/j.1467-8624.2009.01291.x

McCord, M. S., \& Soto, G. (2004). Perceptions of AAC: an ethnographic investigation of Mexican-American families. Augmentative and Alternative Communication, 20, 209-227. doi:10.1080/07434610400005648

McEwan, C., \& Butler, G. (2007). Disability and development: different models, different places. Geography Compass, 1, 448-466. doi:10.1063/1.2756072

McNaughton, D., Rackensperger, T., Benedek-Wood, E., Krezman, C., Williams, M., \& Light, J. (2008). "A child needs to be given a chance to succeed": Parents of individuals who use AAC describe the benefits and challenges of learning AAC technologies. Augmentative and Alternative Communication, 24, 43-55. doi:10.1080/07434610701421007

Mukhopadhyay, S., \& Nwaogu, P. (2009). Barriers to teaching non-speaking learners with intellectual disabilities and their impact on the provision of augmentative and alternative communication. International Journal of Disability, Development and Education, 56, 349362. doi:10.1080/10349120903306590 
Naraian, S. (2010). Disentangling the social threads within a communicative environment: A cacophonous tale of alternative and augmentative communication (AAC). European Journal of Special Needs Education, 25, 253-267. doi:10.1080/08856257.2010.492936

Pasupathy, R., \& Bogschutz, R. J. (2013). An investigation of graduate speech-language pathology students' SLP clinical self-efficacy. Contemporary Issues in Communication Science \& Disorders, 40, 151-159.

Patel, R., \& Khamis-Dakwar, R. (2005). An AAC training program for special education teachers: A case study of Palestinian Arab teachers in Israel. Augmentative and Alternative Communication, 21, 205-217. doi:10.1080/07434610400011638

Pickl, G. (2011). Communication intervention in children with severe disabilities and multilingual backgrounds: Perceptions of pedagogues and parents. Augmentative and Alternative Communication, 27, 229-244. doi:10.3109/07434618.2011.630021

Pillay, M., \& Kathard, H. (2015). Decolonizing health professionals' education: audiology and speech therapy in South Africa. African Journal of Rhetoric, 7, 195-227.

Raghavendra, P., Bornman, J., Granlund, M., \& Björck-Akesson, E. (2007). The World Health Organization' s international classification of functioning, disability and health: Implications for clinical and research practice in the field of augmentative and alternative communication. Augmentative and Alternative Communication, 23, 349-361. doi:10.1080/07434610701650928

Raghavendra, P., Olsson, C., Sampson, J., Mcinerney, R., \& Connell, T. (2012). School participation and social networks of children with complex communication needs, physical disabilities, and typically developing Peers. Augmentative and Alternative Communication, 28, 33-43. doi:10.3109/07434618.2011.653604 
Saldaña, J. (2013). The coding manual for qualitative researchers. London, United Kingdom: Sage.

Schlosser, R. W., Shane, H. C., Allen, A. A., Abramson, J., Laubscher, E., \& Dimery, K. (2016). Just-in-time supports in augmentative and alternative communication. Journal of Developmental and Physical Disabilities, 28, 177-193. doi:10.1007/s10882-015-9452-2

Schlosser, R. W., \& Sigafoos, J. (2006). Augmentative and alternative communication interventions for persons with developmental disabilities: Narrative review of comparative single-subject experimental studies. Research in Developmental Disabilities, 27, 1-29. doi:10.1016/j.ridd.2004.04.004

Schmitt, M. B., \& Justice, L. (2011). Schools as complex host environments: Understanding aspects of schools that may influence clinical practice and research. The ASHA Leader, 16(6), 8-11. doi:10.1044/leader.FTR1.16072011.8

Skaalvik, E. M., \& Skaalvik, S. (2007). Dimensions of teacher self-efficacy and relations with strain factors, perceived collective teacher efficacy, and teacher burnout. Journal of Educational Psychology, 99, 611-625. doi:10.1037/0022-0663.99.3.611

Smith, M. (2006). Speech, language and aided communication: Connections and questions in a developmental context. Disability and Rehabilitation, 28, 151-7. doi:10.1080/09638280500077747

Smith, M. M., \& Connolly, I. (2008). Roles of aided communication: perspectives of adults who use AAC. Disability and Rehabilitation: Assistive Technology, 3, 260-273. doi:10.1080/17483100802338499

Soto, G. (1997). Special education teacher attitudes toward AAC: Preliminary survey. Augmentative and Alternative Communication, 13, 186-197. 
doi:10.1080/07434619712331278008

Statistics South Africa. (2011). Regional economic growth. Pretoria, South Africa: Author.

Statistics South Africa. (2012). Census 2011: provinces at a glance. Pretoria, South Africa: Author.

Statistics South Africa. (2015). Statisitcal release P0302: mid-year population estimates. Pretoria, South Africa: Author.

The Constitution of the Republic of South Africa, Act 108 of 1996 (1996). Retrieved from http://www.justice.gov.za/legislation/constitution/SAConstitution-web-eng.pdf

Van Niekerk, K., \& Tönsing, K. (2015). Eye gaze technology: a South African perspective. Disability \& Rehabilitation: Assistive Technology, 10, 340-346.

doi:10.3109/17483107.2014.974222

Wilkinson, K. M., \& Hennig, S. (2007). The state of research and practice in augmentative and alternative communication for children with developmental/intellectual disabilities. Mental Retardation and Developmental Disabilities Research Reviews, 69, 58-69. doi:10.1002/mrdd.20133

World Health Organization (2001). International classification of functioning, disability and health. Geneva, Switzerland: Author.

Wormnaes, S., \& Malek, Y. A. (2004). Egyptian speech therapists want more knowledge about augmentative and alternative communication. Augmentative and Alternative Communication, 20, 30-42. doi:10.1080/07434610310001629571 